\title{
CORRESPONDENCE
}

\section{Economic growth: indicators not targets}

Peter Victor questions the merits of economic growth in developed countries (Nature $468,370-371 ; 2010)$. In such discussions, it is important to avoid confusing indicators with optimization targets. An indicator that may be useful for evaluating an economy could be harmful when used as a target to improve the state of the economy.

An economic indicator, such as gross domestic product (GDP) or the genuine progress indicator (GPI), is a number that quantifies a particular aspect of an economy. Indicators are useful for comparing different economies or for monitoring development. But they are overly simplistic in that they ignore all non-quantifiable aspects of living.

This flaw becomes crucial when an indicator is turned into an optimization target. Politicians will quickly identify and exploit mechanisms that are likely to increase the indicator, even if there is no benefit for society.

Measures that would not even be considered in the absence of a specific optimization target can then become political priorities when that target is adopted. Public debt is one such indicator that has recently become a high-priority optimization target in many European countries, despite wide recognition of the socially negative effects of the cuts that are needed to reduce it.

This will happen to any indicator, including the GPI, which takes into account social and environmental factors as well as economic ones. Economists and politicians must accept that no single number can safely be optimized. Several indicators that concentrate on different aspects of society need to be used in parallel, and any measure that improves one while decreasing another must be recognized as a compromise between conflicting goals. Konrad Hinsen Centre de Biophysique Moléculaire (CNRS), France.

konrad.hinsen@cnrs-orleans.fr

\section{Economic growth: enough is enough}

There is substantial evidence that further economic growth in wealthy nations is neither sustainable nor desirable. It is indeed time, as Peter Victor writes (Nature 468, 370-371; 2010), to answer key questions about what a non-growing economy would look like in practice. We need a new macroeconomics for sustainability, and we need it now.

On 17 November a report was released in the United Kingdom, entitled Enough is Enough: Ideas for a Sustainable Economy in a World of Finite Resources (see go.nature.com/hv52np). The report brings together the ideas generated at the first Steady State Economy Conference held in June this year in Leeds, UK. It discusses policy proposals in ten key areas needed to achieve a no-growth economy. Proposals include policies to limit resource use, reduce income inequality, reform the monetary system, change consumer behaviour, restructure business, secure full employment and improve the way in which we measure progress.

A growing number of economists, scientists and policy-makers are beginning to understand the urgent need for an economic model based on stability instead of growth (see go.nature.com/f8ig8s). A combination of further research into the steady-state model and bold action to turn this model into government policy is required to achieve well-being for everyone within ecological limits.

Daniel W. O'Neill Center for the Advancement of the Steady State Economy, Leeds, UK. dan_oneill@steadystate.org

\section{Coordinate green growth}

Green economic growth needs a shared sense of direction if it is to lead to a more sustainable future under climate change. Studies on green innovation and societal transformation show that uncoordinated initiatives are unlikely to be an effective way "to get the ball rolling and to 'learn by doing'” (Nature 468, 477; 2010).

First, socio-technical transformations, such as the transition from fossil fuels to renewable-energy sources, will require several decades to complete. Speeding up this process needs focus and coordination at the international level.

Second, the learning curves for creating energy-efficient and renewable-energy technologies are global. Here, coordination will be necessary to determine cost reductions and to increase performance.

Third, green growth calls for major shifts in the way in which economies are organized. It is not trivial to align the interests of fossil-fuel-intensive incumbent industries and their supporting power structures with the interests of emerging 'green' industries. Again, coordination will be necessary to overcome the resistance to change in incumbent production and consumption systems.

Floortje Alkemade, Marko

Hekkert Utrecht University, the Netherlands.

f.alkemade@geo.uu.nl

\section{A slip in the date of DNA's discovery}

In her review of Anna Ziegler's play Photograph 51, Josie Glausiusz refers to DNA's "discovery" in 1953 (Nature $468,375 ; 2010)$, when this was in fact the year its structure was solved. The molecule itself was discovered almost a century earlier.

It was a young Swiss physician, Friedrich Miescher, who stumbled on DNA in 1869 , naming it nuclein. He realized that it chemically defines the nucleus - an enigmatic organelle at that time - and identified the molecule in a wide variety of cell types, including germ cells. He determined DNA's elementary composition and basic biochemical properties, and suggested that it could be important in cell proliferation, realizing it was synthesized before cell division.

Miescher developed theories on the basis of these findings to explain DNA's function in terms of fertilization and heredity, even proposing how macromolecules might encode information. His work also stimulated others to investigate DNA and its function.

Miescher should therefore be remembered not just as the discoverer of DNA, but also as the founder of molecular genetics.

Ralf Dahm Institute of Molecular Biology, Mainz, Germany. r.dahm@imb-mainz.de

CONTRIBUTIONS Items for Correspondence may be submitted to correspondence@nature. com after consulting the author guidelines at http:// go.nature.com/cmchno. They should be no longer than 350 words. 